\title{
Alinhamento entre planejamento estratégico e planejamento orçamentário em uma instituição pública federal de ensino
}

O planejamento estratégico no setor público brasileiro teve maior ênfase com a Constituição Federal de 1988 ao integrar o Plano Plurianual, a Lei de Diretrizes Orçamentárias e a Lei Orçamentária Anual (Brasil, 1988). Deste modo, percebe-se que o planejamento e execução orçamentária estão atrelados às metas e objetivos traçados no Plano Plurianual. O objetivo deste artigo é verificar o alinhamento entre o planejamento estratégico e planejamento orçamentário na reitoria e nos campus de uma instituição pública federal de ensino. A pesquisa caracteriza-se como dedutiva, quali-quantitativa e descritiva. Trata-se de um estudo de caso, que tem por objeto o Instituto Federal de Educação Ciência e Tecnologia de Santa Catarina (IFSC). A coleta de dados foi realizada por meio de análise documental, sendo foco de análise o Planejamento Estratégico, o Plano Anual de Trabalho (orçamento) e os documentos que orientam e regulamentam tais procedimentos, e aplicação de questionários com os Chefes de Departamento de Administração nos Campus e Diretor de Administração na Reitoria. Foram obtidas 21 respostas válidas (100\%), recebidas entre os dias 16 a 29 de setembro de 2015. A análise dos dados foi realizada por meio do software Microsoft Excel 2010. Com base nos documentos analisados, constatou-se que há sintonia entre a previsão legal e a prática da organização e orientação para o alinhamento entre planejamento estratégico e planejamento orçamentário da instituição, com obrigatoriedade da vinculação dos projetos a serem desenvolvidos nos Campus diretamente a um dos objetivos estratégicos. Este alinhamento foi confirmado por meio das respostas dos Chefes de Administração ao questionário. Assim, podese concluir que existe alinhamento entre o planejamento estratégico e o planejamento orçamentário da instituição e que há intenção da gestão em reforçar este alinhamento e torná-lo cada vez mais efetivo.

\section{Alignment between strategic planning and budget planning at a federal public educational institution}

\begin{abstract}
Strategic planning in the Brazilian public sector had greater emphasis on a Federal Constitution of 1988 when integrating the Pluriannual Plan, a Law of Budgetary Guidelines and an Annual Budgetary Law (Brazil, 1988). In this way, it can be seen that budget planning and execution are linked to the goals and objectives outlined in the Multi-Year Plan. The objective of this article is to verify the alignment between strategic planning and budget planning in rectory and on campus of a federal public educational institution. The research is characterized as deductive, qualitative and descriptive. This is a case study, whose purpose is the Federal Institute of Education Science and Technology of Santa Catarina (IFSC). Data collection was done through documentary analysis, as a focus of analysis or strategic planning, the Annual Work Plan (budget) and the documents that guide and regulate such procedures, and the application of questionnaires with the Heads of Administration Department Campus And Director of Administration at the Rectory. A total of 21 valid responses (100\%) were received between September 16 and 29,2015 . An analysis of the data was done using Microsoft Excel 2010. Based on the documents analyzed, it was verified that there is a tuning between the Prediction Legal and practice of the organization and orientation for the alignment between strategic planning and budget planning of the institution, with binding of projects and projects developed. This alignment was confirmed by the Heads of Administration's replies to the questionnaire. Thus, it can be concluded that there is an alignment between the strategic planning and budgetary planning of the institution and that the intention of the management in reinforcing this alignment and making it more and more effective.
\end{abstract}

Keywords: Alignment; Strategic Planning; Budget Planning.

Topic: Gestão Pública

Reviewed anonymously in the process of blind peer
Received: 21/01/2017

Approved: 21/03/2017
Nauana Gaivota Silveira

Universidade Federal de Santa Catarina, Brasi

http://lattes.cnpq.br/7886275026711471

nauanagaivota@gmail.com

\section{Lais Karine Sardá Martins}

Instituto Federal de Santa Catarina, Brasil http://lattes.cnpq.br/7046161436253901 lais-karine@hotmail.com

Rogério João Lunkes

Universidade Federal de Santa Catarina, Brasil http://lattes.cnpq.br/6241003358183170 rogeriolunkes@hotmail.com
Valdirene Gasparetto

Universidade Federal de Santa Catarina, Brasil

http://lattes.cnpq.br/9876735629466934 valdirenegasparetto@gmail.com
Referencing this:

SILBEIRA, G. N.; MARTINS, S. K. L.; LUNKES, J. R.; GASPARETTO, V.. Alinhamento entre planejamento estratégico e planejamento orçamentário em uma instituição pública federal de ensino. Revista Brasileira de Administração Científica, v.8, n.1, p.221-235, 2017. DOI: http://doi.org/10.6008/SPC2179-684X.2017.001.0017 


\section{INTRODUÇÃO}

As organizações atuam em ambientes cada vez mais dinâmicos e competitivos, sendo necessário que se adaptem diariamente às modificações que ocorrem de maneira frequente (BORNIA et al., 2007). A dinâmica imposta nestes ambientes conduz as entidades ao aprimoramento continuo de seus processos internos, assim, a definição da estratégia deve considerar as peculiaridades trazidas por este ambiente marcado pela competitividade. Com isso, um dos desafios das organizações consiste em desenvolver estratégias de modo que ofereçam condições de ordenar as competências, harmonizar os recursos, sem que as mudanças ocorridas no ambiente passem despercebidas (MINTZBERG et al., 2006).

Para tanto, o planejamento estratégico aparece como uma ferramenta orientadora e facilitadora destes processos de melhoria. Para Drucker (1998), o planejamento estratégico constitui-se num "processo contínuo de tomar decisões atuais que envolvam riscos, organizar sistematicamente as atividades necessárias à execução dessas decisões e medir o resultado dessas decisões com as expectativas almejadas". Deste modo, a visão de médio e longo prazos da organização, formalizada no planejamento estratégico, deve considerar, dentre outros fatores, a disponibilidade dos recursos da instituição. Esta verificação habitualmente é feita por meio do processo orçamentário para garantir a implementação de sua estratégia (LUNKES, 2003). Isso é desafiador para qualquer organização seja privada ou pública.

Esta pesquisa aborda este processo no âmbito da administração pública que possui como desafio desburocratizar seus processos criando uma estrutura mais empreendedora e flexível. Assim, a capacitação de gestores, a adoção de padrões e o uso do planejamento estratégico são facilitadores deste processo (SILVA et al., 2013). O planejamento estratégico no setor público brasileiro teve maior ênfase com a Constituição Federal de 1988 ao integrar o Plano Plurianual, a Lei de Diretrizes Orçamentárias e a Lei Orçamentária Anual (BRASIL, 1988). Deste modo, percebe-se que o planejamento e execução orçamentária estão atrelados às metas e objetivos traçados no Plano Plurianual. Assim, apesar da previsão legal, a reflexão que norteia esta pesquisa é: há alinhamento entre o planejamento estratégico do IFSC e o planejamento orçamentário da Instituição?.

Com o intuito de responder a questão proposta, o objetivo passou a ser verificar o alinhamento entre o planejamento estratégico do IFSC e planejamento orçamentário na reitoria e nos campus. Tendo em vista que a função administrativa de planejamento envolve a fixação dos objetivos e a elaboração do orçamento para atingi-los, espera-se que esta pesquisa evidencie se na administração pública, mais especificamente na instituição estudada, o orçamento está sendo elaborado com vistas a atingir os objetivos presentes no planejamento estratégico.

\section{REVISÃO TEÓRICA}

\section{Planejamento estratégico na Administração Pública}

Nesta seção, apresenta-se uma breve revisão teórica acerca dos temas planejamento estratégico na administração pública, o orçamento público no Brasil e a importância do alinhamento entre os 
planejamentos estratégico e orçamentário. O planejamento estratégico constitui-se numa ferramenta de orientação tanto para entidades privadas quanto públicas. Trata-se de um procedimento que, de maneira formalizada, visa à produção de um resultado, sob a forma de um sistema integrado de gestão (MINTZBERG, 1994). Reconhecido como ferramenta capaz de auxiliar o desenvolvimento de uma organização, começou a ganhar forma em meados de 1950, sendo utilizado, principalmente, pelo setor privado por mais de 30 anos. Neste período, o setor público desenvolvia conceitos e cultura baseados inteiramente em legislações (CAYMAZ et al., 2013).

A escassez de recursos e as cobranças crescentes sobre a eficiência da gestão pública, fizeram com que, a partir da década de 80, o planejamento estratégico na administração pública passasse a ser um tema de interesse tanto de estudiosos quanto pesquisadores (EADIE, 1983; RING et al., 1985; BRYSON, 1995). Nas entidades públicas o planejamento estratégico deve considerar os fatores externos, perceber as forças internas e fraquezas, e a partir disto definir as metas organizacionais e tomar as medidas necessárias para alcança-las (SALKIC, 2014). Bryson (1995) aponta as seguintes vantagens para o setor público, decorrentes do planejamento estratégico: promoção do pensamento estratégico e ação; melhoria no processo de tomada de decisão, melhoria da organização, melhoria da organização do trabalho e dos resultados; e benefícios diretos aos funcionários da organização (BRYSON, 1995).

Em ação conjunta a Organização para Cooperação e Desenvolvimento Econômico (OCDE) e a União Européia (UE) definiram que o planejamento estratégico na administração pública possui dois componentes principais: gestão e orçamento (CAYMAZ et al., 2013). A gestão deve ser estratégica, incluindo declaração de missão, visão, valores, análise dos ambientes interno e externo, prioridades de médio prazo, direções de atividades, monitoramento e avaliação e relatórios. O orçamento inclui a análise da situação atual, objetivos, resultado, indicadores de desempenho do programa orçamentário e do programa de financiamento (CAYMAZ et al., 2013).

Com isso, percebe-se que apesar de começar na iniciativa privada, o setor público também percebeu a utilidade do processo do planejamento estratégico e respectiva tentativa de alinhamento. Nas entidades públicas este processo deve ser conduzido considerando os fatores relacionados à gestão estratégica e ao orçamento.

\section{Orçamento público no Brasil}

O orçamento público é um instrumento que incentiva a estruturação governamental, assim, seu uso permite a implementação das políticas públicas tanto do ponto de vista político quanto econômico (ABREU et al., 2015). Na década de 1980, em virtude da crise financeira, houve forte pressão internacional sobre o processo orçamentário do Brasil. Assim, os governos passaram a priorizar uma administração mais enxuta, efetiva e eficiente, priorizando uma reforma estatal com base no modelo gerencial (CORE, 2007).

Essa pressão por melhoria na gestão dos recursos públicos resultou na sua inclusão na carta magna do país que prevê que o planejamento orçamentário deve ser elaborado considerando o disposto na Constituição Federal de 1988, que evidencia os instrumentos do orçamento público, sendo eles o Plano 
Plurianual (PPA), a Lei de Diretrizes Orçamentárias (LDO) e a Lei Orçamentária Anual (LOA).

A Constituição Federal de 1988 utilizou os instrumentos do orçamento público com vistas a uniformizar as ações do Estado. Deste modo, os planos e prioridades da administração pública devem ser compatíveis com o disposto no PPA. O PPA deve ser elaborado com base nas metas e objetivos almejados dentro do período de quatro anos. A LDO deve abordar as metas e prioridades da administração pública federal e orientar a elaboração da LOA. A LOA, por sua vez, deve ser elaborada com base no PPA e na LDO, considerando a programação das ações com base nas metas e objetivos fixados (BRASIL, 1988).

Deste modo, o planejamento orçamentário nas instituições públicas brasileiras deve considerar o aspecto legal. A União indica por meio dos instrumentos do orçamento público que deve existir conexão entre a elaboração do orçamento e as metas e objetivos definidos nos órgãos pertencentes à administração pública. Como isso percebe-se uma preocupação legal com a importância do alinhamento entre a visão de médio e longo prazos com a de curto prazo.

\section{Alinhamento dos planejamentos estratégico e orçamentário}

O planejamento e o orçamento podem ser vistos como processos sequenciais, de modo que o orçamento é uma variação quantitativa do planejamento (FERREIRA et al., 2012). Para Diehl (2004), embora o orçamento decorra da estratégia, podem ocorrer problemas de sinergia entre as áreas, departamentos ou unidades da organização.

Shim et al. (2009) defende que a efetividade dos orçamentos requer a existência dos seguintes fatores: capacidade preditiva; canais claros de comunicação, autoridade e responsabilidade; informações contábeis precisas, confiáveis e oportunas; compatibilidade e compreensibilidade de informação; e apoio em todos os níveis da organização.

$\mathrm{Na}$ elaboração do orçamento o conhecimento dos objetivos estabelecidos no planejamento estratégico é um fator essencial para que ele seja eficiente. O conhecimento dos indicadores estratégicos irá direcionar os objetivos máximos almejados pela organização, assim, as metas orçamentárias devem ser coerentes e alinhadas com as definições estabelecidas no planejamento estratégico (LUNKES, 2003). Para que o orçamento atenda os objetivos estabelecidos pela organização, ele deve ser elaborado com base no planejamento estratégico. A tabela 1 destaca alguns dos fatores que influenciam o alinhamento dos planejamentos estratégico e orçamentário.

Apesar de a tabela 1 apontar 12 fatores que podem influenciar no alinhamento dos planejamentos estratégico e orçamentário, eles não são exaustivos e podem haver outros que impactam neste processo. Exemplos desta natureza podem ser a ocorrência de situações em que a elaboração do orçamento da organização antecede a formulação do planejamento estratégico (LEAHY, 2002). Podem existir também situações em que estes processos ocorrem simultânea e paralelamente na organização e ainda são coordenados por pessoas distintas e sem conexão entre os fluxos de construção dos dois processos (RODRIGUES, 2015).

A possibilidade de existência deste tipo de situações e que não raras vezes são silenciosamente 
conflitantes gera dificuldades na condução e, naturalmente, construção do alinhamento estratégico e orçamentário da organização. Identificar os ruídos e conseguir minimizá-los é um desafio para os gestores que, face as características e peculiaridade da gestão pública, são nela potencializados.

Tabela 1: Fatores que influenciam o alinhamento dos planejamentos estratégico e orçamentário.

\begin{tabular}{|l|l|}
\hline \multicolumn{1}{|c|}{ Fatores que podem influenciar o alinhamento } & \multicolumn{1}{c|}{ Autores } \\
\hline Necessidade de sequenciamento entre planejamento e orçamento & $\begin{array}{l}\text { Leahy (2002); Blumentritt (2006); Frezatti (2009); Ferreira } \\
\text { et al. (2012). }\end{array}$ \\
\hline Orçamento com papel de planejamento & Blumentritt (2006). \\
\hline $\begin{array}{l}\text { Ferramentas de comunicação e definição de responsabilidade entre } \\
\text { as áreas }\end{array}$ & Shim et al. (2009). \\
\hline Geração de informações acuradas, confiáveis e em tempo oportuno & Shim et al. (2009). \\
\hline Compatibilidade e compreensibilidade das informações & Shim et al. (2009). \\
\hline Suporte em todos os níveis da organização & Shim et al. (2009). \\
\hline Eficiência dos sistemas de apoio & Rezende et al. (2004); Blumentritt (2006). \\
\hline Políticas e diretrizes adequadas & Blumentritt (2006); Leite et al. (2008). \\
\hline $\begin{array}{l}\text { Pessoas e áreas envolvidas na construção das duas ferramentas de } \\
\text { gestão }\end{array}$ & Blumentritt (2006). \\
\hline Flexibilidade do orçamento & $\begin{array}{l}\text { Blumentritt (2006); Bornia et al. (2007); Kaplan et al. } \\
\text { (2006). }\end{array}$ \\
\hline $\begin{array}{l}\text { Utilização de contextos interno e externo diferentes na elaboração } \\
\text { das duas ferramentas }\end{array}$ & $\begin{array}{l}\text { Otley et al. (2000); Rezende et al. (2004); Blumentritt } \\
\text { (2006); Shim et al. (2009). }\end{array}$ \\
\hline Habilidade preditiva & Shim et al. (2009). \\
\hline
\end{tabular}

Fonte: Rodrigues (2015).

\section{METODOLOGIA}

Nesta seção apresenta-se os procedimentos e escolhas metodológicas adotadas para a realização desta pesquisa. São organizados em enquadramento metodológico, procedimentos para coleta e análise de dados e a caracterização da instituição objeto do estudo. A tabela 2 apresenta o enquadramento metodológico da pesquisa realizada, de acordo com diferentes critérios. $O$ enquadramento foi apresentado de acordo com os critérios de lógica, abordagem, estratégia e objetivo da pesquisa, coleta de dados primários e procedimentos técnicos.

Tabela 2: Enquadramento Metodológico.

\begin{tabular}{|l|l|}
\hline \multicolumn{1}{|c|}{ Critério } & \multicolumn{1}{c|}{ Classificação } \\
\hline Lógica da Pesquisa & Dedutiva \\
\hline Abordagem da Pesquisa & Quali-quantitativa \\
\hline Estratégia da Pesquisa & Bibliográfica e de Campo \\
\hline Objetivo da Pesquisa & Descritiva \\
\hline Coleta de dados primários & Análise Documental e Aplicação de Questionário \\
\hline Procedimentos Técnicos & Estudo de Caso \\
\hline
\end{tabular}

\section{Procedimentos para coleta e análise de dados}

A coleta e análise de dados foi composta por análise documental e aplicação de questionário. Os documentos objeto de análise foram o Planejamento Estratégico, parte integrante do Plano de Desenvolvimento Institucional 2015-2019, o Plano Anual de Trabalho 2015 e documentos de apoio e orientação à elaboração do Plano Anual de Trabalho. O questionário foi elaborado com base na análise da literatura, sendo estruturado com questões abertas e fechadas, totalizando 18 questões, com o objetivo de identificar o perfil dos respondentes, sua percepção sobre o Planejamento Estratégico, Planejamento Orçamentário e o alinhamento entre estes. 
$\mathrm{O}$ instrumento de coleta de dados foi elaborado por meio da ferramenta de formulários on-line da Google e encaminhado por e-mail em 16 de setembro de 2015 para os 21 servidores ocupantes dos cargos de Chefe de Departamento de Administração nos Campus e Diretor de Administração na Reitoria do Instituto Federal de Santa Catarina (IFSC). Foram obtidas 21 respostas válidas (100\%), recebidas entre os dias 16 a 29 de setembro de 2015. A análise dos dados foi realizada por meio do software Microsoft Excel 2010.

\section{Apresentação da Instituição objeto de estudo}

Criado como Escola de Aprendizes Artífices de Santa Catarina, por meio do decreto no 7.566, de 23 de setembro de 1909, o Instituto Federal de Educação Ciência e Tecnologia de Santa Catarina (IFSC) é uma instituição de educação básica, profissional e superior, especializados na oferta de educação profissional e tecnológica, com forte inserção na área de pesquisa e extensão.

Vinculado à Secretaria de Educação Profissional e Tecnológica (SETEC) do Ministério da Educação (MEC), tem 23 Campus por todo o estado de Santa Catarina e Reitoria sediada em Florianópolis. Sua missão é "promover a inclusão e formar cidadãos, por meio da educação profissional, científica e tecnológica, gerando, difundindo e aplicando conhecimento e inovação, contribuindo para o desenvolvimento socioeconômico e cultural" (IFSC, 2014). Para tanto, possui autonomia administrativa, patrimonial, financeira, didático-pedagógica e disciplinar.

\section{RESULTADOS E DISCUSSÃO}

\section{Análise dos dados obtidos por meio da análise documental}

O planejamento estratégico do IFSC norteia desde o planejamento da oferta de cursos até a organização e gestão de pessoal e infraestrutura. É elaborado para um horizonte de cinco anos, com a participação dos servidores e alunos, reforçando a gestão participativa e remetendo a todos os envolvidos a responsabilidade pela construção do futuro da instituição.

Os Planos Anuais de Trabalho (PAT), o planejamento de caráter mais tático e operacional que, vinculado ao orçamento da instituição, resulta na proposta orçamentária do IFSC para o Projeto de Lei Orçamentária Anual da União (LOA). Tem sua elaboração orientada pelo Planejamento Estratégico. As iniciativas estratégicas são o elo entre o Planejamento Estratégico e os Planos Anuais de Trabalho, constituindo o ponto de partida para a definição dos projetos prioritários da instituição.

O valor total do orçamento da instituição é estabelecido pelo Fórum de Administração e Planejamento do Conselho Nacional das Instituições da Rede Federal de Educação Profissional, Científica e Tecnológica - CONIF, com base no tempo de existência dos campus e número de matrículas. Cabe aos gestores, alocar da melhor forma os recursos recebidos, propiciando o alcance dos objetivos estratégicos.

O valor total estipulado para cada Campus é dividido em duas parcelas, uma para funcionamento, que se destina às demandas necessárias para manter o funcionamento do Campus, e outra para projetos, que devem estar relacionados com uma das iniciativas estratégicas. Esta relação é obrigatória, conforme exposto na Resolução CODIR no 8, de 13 de abril de 2015, em seu artigo nono: "para elaboração e cadastro 
dos projetos no sistema de planejamento, deverá ser observado o alinhamento com as iniciativas estratégicas estabelecidas no Planejamento Estratégico" (IFSC, 2015). Desta forma, a alocação dos recursos de cada Campus, assim como da Reitoria, será totalizada pela soma do custo total de manutenção acrescido dos custos referentes aos projetos. Os PATs são elaborados para o período de um ano, sendo revistos uma vez.

A Reitoria coordena o processo de elaboração destes planos, realizando oficinas regionais de planejamento e elencando responsáveis por cada uma das iniciativas estratégicas, assim como um articulador em cada Campus. No ano de 2015 foram realizadas 9 edições das oficinas em diferentes Campus do IFSC entre os dias 04 a 20 de maio. Buscam, desta forma, orientar e acompanhar o processo em cada um dos Campus, incentivando a ampla participação e o alinhamento entre os planos estratégicos e táticos.

Na leitura documental, percebe-se que existe preocupação do IFSC com a disseminação da estratégia e seu alinhamento com os planos operacionais. Mais especificamente, no Planejamento Estratégico 20152019, nas iniciativas estratégicas 'aperfeiçoar o processo de planejamento e execução orçamentária', na perspectiva Processos e 'realizar eventos de disseminação da estratégia institucional' e 'adequar os macroprocessos finalísticos e de apoio à estratégia institucional' na perspectiva Pessoas e Conhecimento. Dentre os indicadores destas iniciativas, destacam-se o 'grau de conhecimento da estratégia pelos servidores', com meta global 90\%, e 'percentual de alinhamento do PAT com a estratégia', como meta global $100 \%$.

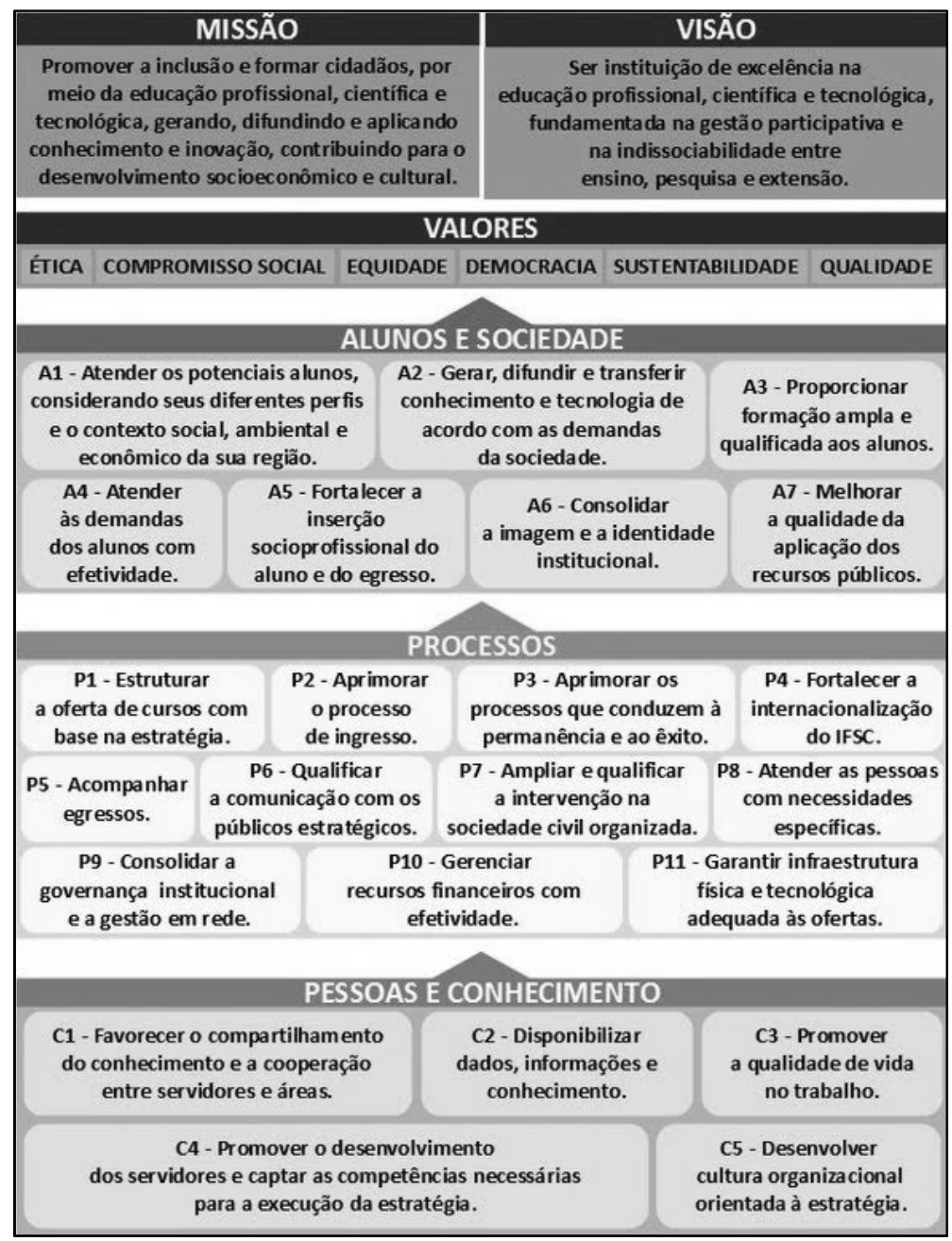

Figura 1: Mapa Estratégico do IFSC. Fonte: IFSC (2015). 
Por outro lado, o último indicador demonstra a ciência da instituição de que não há total alinhamento do PAT com a estratégia, sendo a meta para o ano de 2015 de 80\%, com elevações de 5 pontos percentuais por ano. É valido destacar que a metodologia de planejamento adotada foi implantada em 2014 na instituição e está passando por constante aprimoramento. Na investigação documental constatou-se que, a exemplo da previsão legal, a instituição também tem manifesta preocupação com o alinhamento dos esforços. Resta saber como isso é percebido por quem vivencia esta realidade.

Para cada perspectiva, há um conjunto de objetivos estratégicos, compostos de indicadores, metas e iniciativas estratégicas. Os indicadores são uma definição de medida de desempenho estabelecida para avaliar os resultados, quantificados pelas metas. Cada indicador deve apontar uma meta global para $2019 \mathrm{e}$ metas parciais anuais. Por fim, iniciativas estratégicas são estratégias para atingir os objetivos e metas definidos, estabelecendo as prioridades nas quais as ações devem se pautar. O Planejamento Estratégico é único para a Reitoria e todos os Campus. O mapa estratégico da instituição pode ser observado na figura 1.

\section{Análise dos dados obtidos por meio dos questionários: caracterização dos respondentes}

Quanto à escolaridade dos respondentes, 23,8\% possuem nível superior como a mais alta escolaridade, $66,7 \%$ possuem, além do nível superior, especialização e $9,5 \%$ possuem ainda o mestrado. A área de formação dos mesmos está concentrada em Administração $(71,4 \%)$, seguida de Gestão Pública (9,5\%), Contabilidade (4,8\%) Engenharia (4,8\%), Pedagogia (4,8\%) e Ciências Exatas (4,8\%). No que diz respeito ao gênero, $63,6 \%$ são homens enquanto $36,4 \%$ são mulheres. Quanto ao tempo de atuação na instituição, 57,1\% possuem até 5 anos completos, 28,6\% entre 6 anos e 10 anos completos e 14,3\% possuem mais de 10 anos completos. Já no que diz respeito ao tempo na função, 66,7\% possuem até 2 anos completos, $28,6 \%$ entre 3 anos e 5 anos completos e 4,8\% possuem mais de 5 anos completos.

\section{Planejamento Estratégico}

As primeiras questões avaliavam o conhecimento e participação no Planejamento Estratégico 20152019 do IFSC. Verificou-se que 90,5\% afirmam que conhecem o planejamento em questão, sendo que 71,4\% participaram de sua elaboração. Destes, apenas 20\% foram os responsáveis pelo mesmo nos seus Campus. Os demais (80\%) participaram de outras formas. Entre os relatos de participação, destacam-se presença em reuniões, seminários, fornecimento de informações, articulação e suporte. Desta forma, verifica-se o conhecimento e participação da maior parte dos envolvidos neste processo, entretanto, no geral, estes não foram os responsáveis por ele.

Quando questionados sobre a compreensão da estratégia pelos servidores, apenas 4,8\% afirmaram que todos os servidores compreendem claramente a estratégia da instituição, sendo que 95,2\% não acreditam nesta afirmação. Este dado demonstra a necessidade da realização de promoção do planejamento entre todos os envolvidos. Apesar da percepção de que a estratégia não está totalmente compreendida pela maioria dos servidores, a maior parte dos respondentes $(76,2 \%)$ entende que as atitudes da instituição estão condizentes com seus objetivos de longo prazo, sendo que apenas $23,8 \%$ entendem de forma contrária. Foi 
possível identificar nos comentários à resposta que o processo de planejamento e implementação da estratégia ainda é novo e está em aprimoramento, mas está obtendo êxito na sua função de orientação das atividades atuais em busca do alcance dos objetivos.

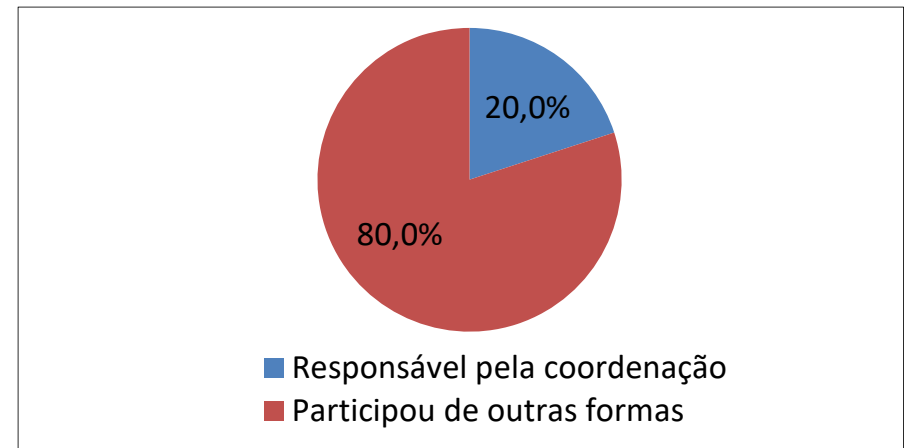

Figura 2: Forma de Participação no Planejamento Estratégico 2015-2019.

Identificou-se alinhamento entre os objetivos e metas gerais da Instituição com os objetivos e metas dos Campus, sendo que 57,1\% entendem que os objetivos da instituição e do Campus são coerentes e 42,9\% entendem que esta coerência é parcial. Não houve nenhuma resposta que afirmasse que não há coerência entre os objetivos. Os comentários demonstram que a heterogeneidade dos Campus, em especial tamanho e tempo de existência, dificulta uma maior identificação com os objetivos, pois cada Campus busca se adaptar as demandas da região onde está inserido. Esta situação é esperada, diante do forte processo de expansão que a instituição passa, tendo Campus com 106 anos e outros com menos de 3 anos.

A coerência entre as atitudes atuais da instituição com seus objetivos e metas gerais, assim como destes com os objetivos e metas gerais dos Campus, indica a existência de políticas e diretrizes adequadas, uma vez que os desdobramentos estão em sintonia e direcionam ao alcance dos objetivos estratégicos, conforme exposto por Blumentritt (2006); Leite et al. (2008).

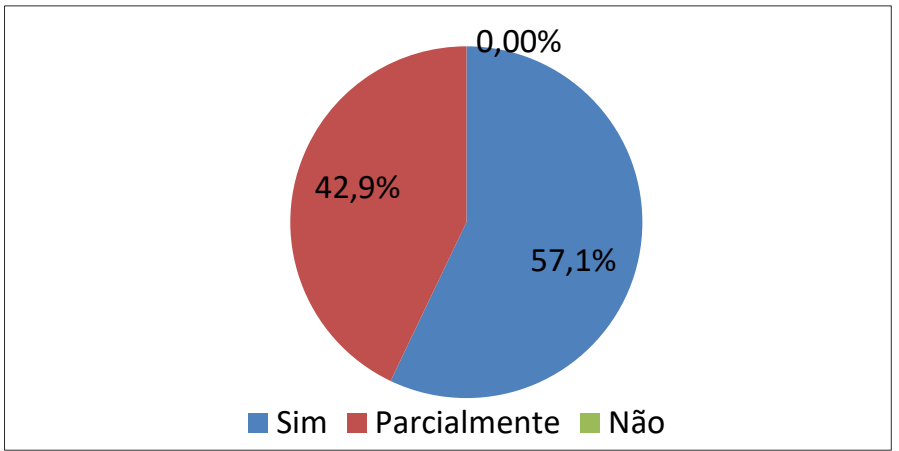

Figura 3: Coerência entre os objetivos e metas gerais da Instituição com os do seu Campus.

\section{Orçamento (Plano Anual de Trabalho)}

Quando questionados sobre o conhecimento e participação no Plano Anual de Trabalho 2015 (orçamento), constatou-se que $95,2 \%$ dos respondentes têm conhecimento do plano, sendo que 90,5\% participaram de sua elaboração. Destes, 57,9\% foram os responsáveis pelo mesmo nos seus Campus. Entre os relatos de participação, destacam-se participações em reuniões e seminários, interlocução entre Reitoria e Campus, levantamento de dados, elaboração de estimativas de custos e cadastro nos sistemas. 
Percebe-se maior conhecimento e participação no Plano Anual de Trabalho (orçamento) do que no Planejamento Estratégico. Da mesa forma, boa parte dos gestores atuam como responsáveis pelo planejamento orçamentário, o que não ocorreu no planejamento estratégico. Este fato era esperado, já que o orçamento é realizado por cada Campus, que apenas participam e contribuem como o processo de planejamento estratégico.

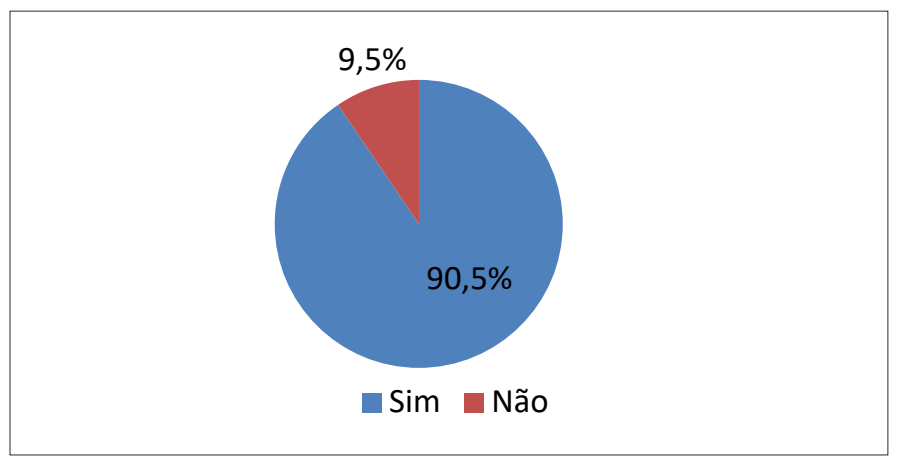

Figura 4: Participação na elaboração do Plano Anual de Trabalho 2015.

Sobre o momento de elaboração do Plano Anual de Trabalho (orçamento) houve 52,4\% das respostas afirmando que o elaboram concomitantemente à construção e $47,6 \%$ afirmam ser posteriormente. Não houve respostas indicando a elaboração do orçamento antes da construção do planejamento ou informando o não conhecimento, o que é positivo, diante do objetivo do orçamento de desdobrar o planejamento da organização e vai ao encontro do disposto na literatura.

Os autores Leahy (2002), Blumentritt (2006), Frezatti (2009) e Ferreira et al. (2012) destacam o sequenciamento do orçamento como um dos fatores que favorece o alinhamento, sendo constatado parcialmente na instituição estudada, diante do alto índice de respostas que indicam a concomitância. Acredita-se que a divergência nas respostas deve-se ao fato do ano em análise ser o ano inicial do Planejamento Estratégico, que faz com que haja sobreposição de algumas atividades com o planejamento orçamentário. Entretanto, esta situação não deve acontecer nos anos seguintes, uma vez que o planejamento abrange o período de cinco anos, sendo o planejamento orçamentário realizado após o planejamento estratégico.

No que diz respeito às áreas responsáveis pelo Planejamento Estratégico e orçamentário, em 61,9\% dos Campus as áreas responsáveis pelos dois planejamentos é a mesma, enquanto que em 38,1\% são áreas diferentes. A realização pela mesma área é positiva e facilita o alinhamento, já que o planejamento estratégico orienta e elaboração do orçamento, conforme entendimento de Blumentritt (2006).

\section{Alinhamento entre o Planejamento Estratégico e o Orçamento}

Quando questionados sobre a influência que o Planejamento Estratégico exerce sobre o Plano Anual de Trabalho (orçamento), 85,7\% afirmaram que há influência. Entretanto, 14,3\% dizem não haver influência do Planejamento Estratégico na elaboração do Plano Anual de Trabalho (orçamento). Percebe-se, nos comentários, que há um conhecimento geral sobre a relação existente entre os dois planejamentos e da importância do alinhamento entre ambos, entretanto, a falta de conhecimento do Planejamento Estratégico 
por alguns e as diferenças entre o tempo de existência de cada Campus, que traz diferentes demandas, prejudica esta relação.

O alinhamento do Plano Anual de Trabalho (orçamento) dos Campus com o Planejamento Estratégico é percebido de forma mais significativa, sendo afirmada por $95,2 \%$ dos respondentes. Nos comentários à resposta, este alinhamento fica evidenciado na vinculação dos projetos com os objetivos estratégicos, entretanto, quando a manutenção do Campus demanda grande parte dos recursos, esta questão fica prejudicada. Estes dados mostram efetividade no processo estabelecido para elaboração do orçamento, com obrigatoriedade da relação entre projetos e objetivos estratégicos.

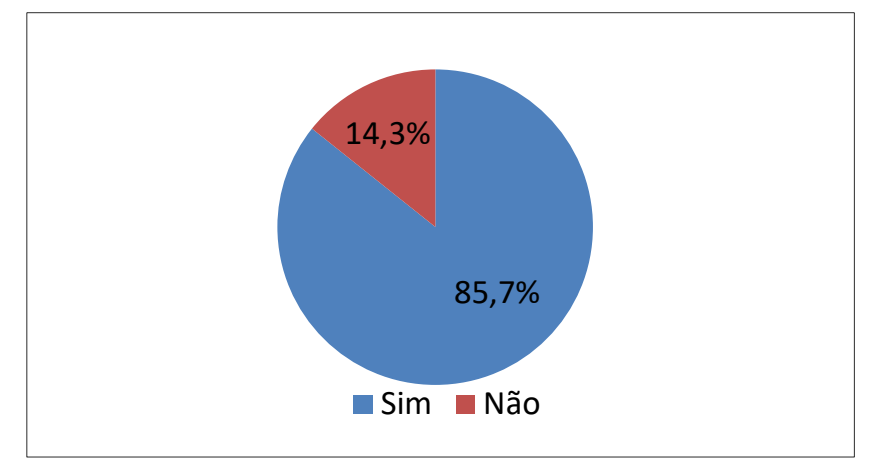

Figura 5: Influência do Planejamento Estratégico na elaboração do Plano Anual de Trabalho (orçamento).

Tendo em vista que o Planejamento Estratégico do IFSC possui 23 objetivos estratégicos, questionouse se todos os objetivos foram comtemplados no Plano Anual de Trabalho (orçamento). Apenas 19\% afirmaram que sim, sendo que $81 \%$ entendem que não. Foi identificada dificuldade nos Campus para elencar prioridades, não havendo uma metodologia comum. Alguns decidem sobre as prioridades em reunião de gestores, outros em consulta a comunidade ou com a utilização ferramentas de gestão, como a análise SWOT e matriz GUT. Apesar de existir uma orientação para priorização, esta não está percebida adequadamente pelos Chefes de Administração.

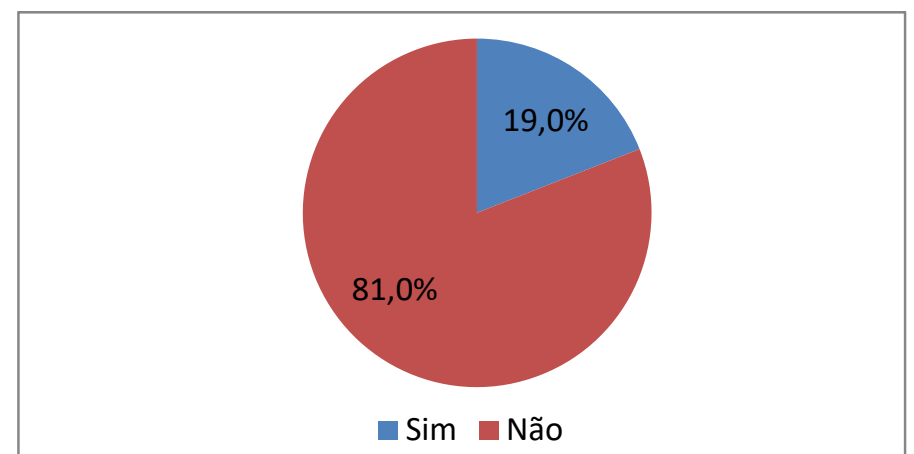

Figura 6: Presença de todos os objetivos estratégicos no Plano Anual de Trabalho (orçamento).

Quando solicitados a manifestar sua concordância com a afirmação "O Plano Anual de Trabalho (orçamento) é utilizado como ferramenta de planejamento, substituindo em parte o Planejamento Estratégico", em uma escala onde "discordo totalmente" equivale a 1, "discordo" a 2, "não discordo nem concordo" a 3, "concordo" a 4 e "concordo totalmente" equivale a 5, obteve-se como resposta que 52,3\% (soma das respostas 4 e 5) dos respondentes, concordam com a afirmação. Há 23,8\% que discordam da afirmação (soma das respostas 1 e 2) e $23,8 \%$ não concordam nem discordam (resposta 3 ). 0 papel de 
planejamento do orçamento corrobora com o entendimento de Blumentritt (2006) e mostra-se como percepção predominante na instituição, entretanto, ainda há falta de consenso, demonstrando a necessidade de melhor entendimento da finalidade do orçamento.

Acerca da contribuição do Plano Anual de Trabalho (orçamento) para o alcance do resultado global da instituição, a maior parte dos respondentes (90,5\%) entende que há contribuição. Esta percepção reforça a constatação de políticas e diretrizes adequadas, citada na fundamentação. Entretanto, a mensuração desta contribuição ainda é pouco clara. Sobre as formas de mensuração foram citados diversos critérios, como número de alunos, oferta de cursos, número de laboratórios estruturados e informações disponibilizadas no relatório de gestão, entretanto fica latente a necessidade de aprimoramento, pois percebeu-se desde o desconhecimento da forma de mensuração até a adoção de métodos muito discrepantes entre os Campus.

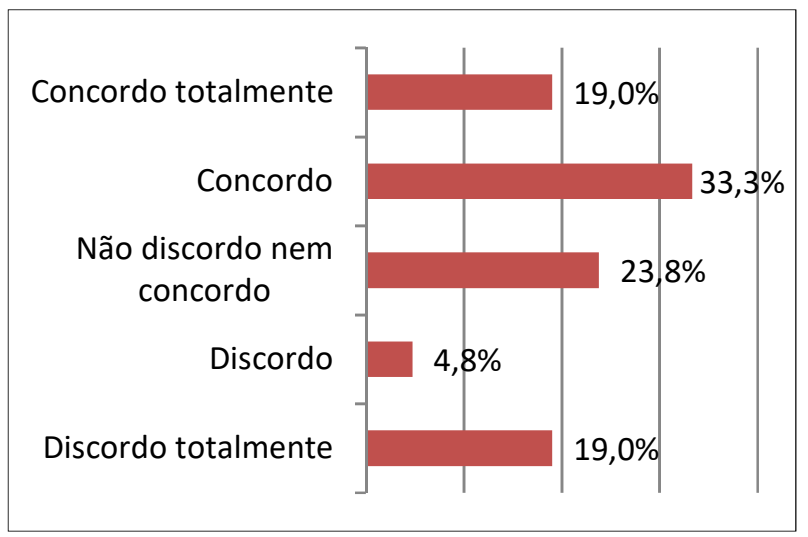

Figura 7: Plano Anual de Trabalho (orçamento) utilizado como ferramenta de planejamento.

Por fim, ao apontar os fatores presentes na instituição que contribuem para o alinhamento da elaboração do Plano Anual de Trabalho (orçamento) com o Planejamento Estratégico, foram destacados a condução de forma participativa do processo, o apoio oferecido pela Reitoria aos Campus, as capacitações realizadas, o sistema (software) de planejamento e comprometimento dos envolvidos. Nestas respostas pode-se identificar fatores citados por Shim et al. (2009) como suporte em todos os níveis da organização e ferramentas de comunicação e definição de responsabilidade entre as áreas, assim como eficiência dos sistemas de apoio, destacada por Rezende et al. (2004); Blumentritt (2006), favorecendo o alinhamento entre planejamento e orçamento.

Já quanto aos fatores que contribuem para o não alinhamento, foram citados os curtos prazos para elaboração do orçamento, morosidade dos processos de aquisição e contratação e, de forma mais recorrente, os cortes orçamentários. Este fator tem relação com a flexibilidade do orçamento, destacada por Blumentritt (2006); Bornia e Lunkes (2007); Kaplan e Norton (2006) como relevantes para o alinhamento do orçamento com o planejamento, identificados como pontos fracos na instituição estudada.

\section{CONCLUSÕES}

A presente pesquisa teve como objetivo verificar o alinhamento entre os planejamentos estratégico e orçamentário na reitoria e nos Campus no Instituto Federal de Educação Ciência e Tecnologia de Santa Catarina. Para tanto, foi realizada análise documental, que teve por objeto o Planejamento Estratégico, o 
Plano Anual de Trabalho (orçamento) e os documentos que orientam e regulamentam tais procedimentos, e aplicação de questionários com os Chefes de Departamento de Administração nos Campus e Diretor de Administração na Reitoria.

Com base nos documentos analisados, constatou-se que há sintonia entre a previsão legal e a prática da organização. Percebeu-se orientação para alinhamento entre os planejamentos estratégico e orçamentário, com obrigatoriedade da vinculação dos projetos a serem desenvolvidos nos Campus diretamente a um dos objetivos estratégicos.

Esta orientação foi confirmada pelos Chefes de Departamento de Administração, com 95,2\% dos respondentes afirmando que o Plano Anual de Trabalho (orçamento) do seu Campus está alinhado com os objetivos estratégicos. Esta percepção foi ratificada nos comentários e em questões semelhantes, como a questão "O Plano Anual de Trabalho do seu Campus contribui para o alcance do resultado global da Instituição" com 90,5\% de respostas positivas.

Necessidades de melhorias foram identificadas, entretanto, em análise ao Planejamento Estratégico, percebeu-se que a instituição tem ciência destas deficiências e busca saná-las com a inclusão de iniciativas de aperfeiçoamento do processo de planejamento e execução orçamentária e promoção de eventos de disseminação da estratégia institucional no planejamento. De fato, a disseminação da estratégia é altamente relevante e revela uma fragilidade da organização pois apenas $4,8 \%$ dos respondentes acreditam que todos os servidores compreendem claramente a estratégia da Instituição.

A expansão da instituição dificulta o alinhamento, uma vez que possui campus bem estruturados e outros em processo de implantação, que faz com que haja uma heterogeneidade de necessidades e percepções, difíceis de abranger em um único planejamento. Apesar de algumas observações neste sentido, esta questão tem sido conduzida de forma a amenizar as discrepâncias. Tal situação é evidenciada na questão 'Os objetivos e metas gerais da Instituição são coerentes com os objetivos e metas do seu Campus?', com $57,1 \%$ de resposta sim e $42,9 \%$ parcialmente. Não houve respostas negativas.

Outra questão crítica identifica é a priorização entre os objetivos, que deveria ser realizada pelo Campus em análise ao seu ambiente. Entretanto, foi percebido que há a adoção de diferentes critérios de priorização e desconhecimento por parte de alguns. Desta forma, entende-se necessário uma melhor estruturação do processo de priorização, de forma a gerar resultados mais efetivos.

A contribuição do orçamento no alcance do resultado é unânime, mas a forma de mensuração desta contribuição apresenta pontos a serem melhorados. Há a indicação dos mais variados critérios, mas há pouca objetividade. Os indicadores estabelecidos nos objetivos estratégicos não foram citados e precisam ter seu entendimento reforçado.

Os resultados encontrados demonstram a presença de diversos fatores que, segundo Blumentritt (2006), Leite et al. (2008), Shim et al. (2009), Rezende et al. (2004), Leahy (2002), Frezatti (2009) e Ferreira et al. (2012), favorecem o alinhamento, como políticas e diretrizes adequadas, orçamento com papel de planejamento, sequenciamento entre planejamento e orçamento, ferramentas de comunicação e definição 
de responsabilidade entre as áreas, suporte em todos os níveis da organização, eficiência dos sistemas de apoio e pessoas e áreas envolvidas na construção das duas ferramentas de gestão.

Entre os fatores identificados na fundamentação, a falta de flexibilidade do orçamento, citada por Blumentritt (2006), Bornia et al. (2007) e Kaplan et al. (2006), é a maior deficiência da instituição, uma vez que foi citada repetidamente como um dos fatores que tem efeito negativo sobre o alinhamento entre planejamento estratégico e orçamento.

De forma geral, foi identificado que existe alinhamento entre os planejamentos estratégico e orçamentário da instituição e que há intenção da gestão em reforçar este alinhamento e torná-lo cada vez mais efetivo. Este estudo limita-se a percepção dos ocupantes dos cargos de Chefe de Administração dos Campus e Diretor de Administração na Reitoria e não permite a inferência dos resultados obtidos para outras instituições. Para futuros trabalhos, sugere-se a realização da pesquisa com os diretores dos campus e gestores de níveis mais operacionais, obtendo assim a percepção de outros envolvidos no processo, além da sua nova aplicação com o mesmo público no ano final do planejamento estratégico (2019).

\section{REFERÊNCIAS}

ABREU, C. R; CÂMARA, L. M.. O orçamento público como instrumento de ação governamental: uma análise de suas redefinições no contexto da formulação de políticas públicas de infraestrutura. Revista Administração Pública, Rio de Janeiro, v.49, n.1, p.73-90, 2015.

BLUMENTRITT, T.. Integrating strategic management and budgeting. Journal of Business Strategy, v.27, n.6, p.73-79, 2006.

BORNIA, A. C.; LUNKES, R. J.. Uma contribuição à melhoria do processo orçamentário. Contabilidade Vista \& Revista, v.18, n.4, p.37-59, 2007.

BRASIL. Constituição Federal de 1988. Brasília: DOU, 1988.

BRYSON, J. M.. Strategic planning for public and nonprofit organizations: a guide to strengthening and sustaining organizational achievement. San Francisco: Jossey-Bass Publishers, 1995.

CATELLI, A.. Controladoria: uma abordagem da gestão econômica GECON. 2 ed. São Paulo: Atlas, 1999.

CAYMAZ, E.; AKYON, F. V.; ERENEL, F.. An exploratory research on strategic planning in public institutions: Turkish prime ministry disaster and emergency management presidency case. Santa Maria: Procedia - Social and Behavioral Sciences, 2013.

CORE, F. G.. Reforma gerencial dos processos de planejamento e orçamento. In: GIACOMONI, J.; PAGNUSSAT, J. L.. Planejamento e orçamento governamental. Brasília: ENAP, 2007. p.219-261.

DIEHL, C. A.. Controle Estratégico de Custos: um modelo referencial avançado. Tese (Doutorado) - Universidade Federal de Santa Catarina, Florianópolis, 2004.
DRUCKER, P.. The Progress of Management. Viena: Irwin, 1998.

EADIE, D. C.. Putting a powerful tool to practical use: The application of strategic planning in the public sector. Public Administration Review, n.2, p.447-452, 1983.

FERREIRA, F. B.; DIEHL, C. A.. Orçamento empresarial e suas relações com o planejamento estratégico. Pensar Contábil, v.14, n.54, p.48-57, 2012.

FREZATTI, F.. Orçamento empresarial: planejamento e controle gerencial. 5 ed. São Paulo: Atlas, 2009.

GARCIA, R. C.. A reorganização do processo de planejamento do governo federal: o PPA 2000- 2003. Brasília: IPEA, 2000.

IFSC. Instituto Federal de Santa Catarina. Planejamento Estratégico. Florianópolis: IFSC, 2014.

IFSC. Instituto Federal de Santa Catarina. Resolução Codir n.8 de 13 de abril de 2015. Dispõe sobre a elaboração do Plano Anual de Trabalho 2016 e dá outras providências. Florianópolis: IFSC, 2015.

KAPLAN, R. S.; NORTON, D. P.. Alinhamento: utilizando o Balanced Scorecard para criar sinergias corporativas. Rio de Janeiro: Campus, 2006.

LEAHY, T.. As 10 maiores armadilhas do orçamento. Revista HSM Management, n.32, 2002.

LEITE, R. M.; CHEROBIM, A. P. M. S.; SILVA, H. D. F. N.; BUFREM, L. S.. Orçamento empresarial: levantamento da produção científica no período de 1995 a 2006. Revista Contabilidade e Finanças USP, v.19, n.47, p.56-72, 2008.

LUNKES, R. J.. Contribuição à melhoria do processo orçamentário empresarial. Tese (Doutorado) - Universidade Federal de Santa Catarina, Florianópolis, 2003. 
MINTZBERG, H.. The rise and fall of strategic planning: reconceiving roles for planning, plans, planners. New York: The Free Press, 1994.

MINTZBERG, H.; LAMPEL, J.; QUINN, J. B.; GHOSHAL, S.. O processo da estratégia: conceitos, contextos e casos selecionados. 4 ed. Porto Alegre: Bookman, 2006.

OTLEY, D.. Performance management: a framework for management control systems research. Management Accounting Research, v.10, n.4, p.363-382, 1999.

REZENDE, J. F. C.; NOGUEIRA, A. R. R.. Alinhamento estratégico e balanceamento da performance: um estudo a partir da percepção de gerentes de agências bancárias. In: ENCONTRO DA ANPAD. Anais. Curitiba: ANPAD, 2004.

RING, P. S.; PERRY, J. L.. Strategic management in public and private organizations: Implications of distinctive contexts and constraints. Academy of Management Review, v.10, p.276286, 1985.
RODRIGUES, S. M.. Alinhamento entre planejamento estratégico e orçamento executado. Dissertação (Mestrado) - Universidade Federal de Santa Catarina, Florianópolis, 2015.

SALKIC, I.. Impact of strategic planning on management of public organizations in Bosnia and Herzegovina: Interdisciplinary description of complex systems. Sarajevo: University of Sarajevo, 2014.

SHIM, J. K; SIEGEL, J. G.. Budgeting basics and beyound. New Jersey: John Wiley \& Sons, 2009.

SILVA, W. C.; MUCCI, C. B. M.; BAETA, O. V.; ARAÚJO, D. S.. Planejamento estratégico na administração pública: um estudo multicaso. Revista de Ciências Humanas, Viçosa, v.13, n.1, p.90-101, 2013.

ZDANOWICZ, J. E.. Orçamento Operacional. Porto Alegre: Editora Sagra, 1989. 